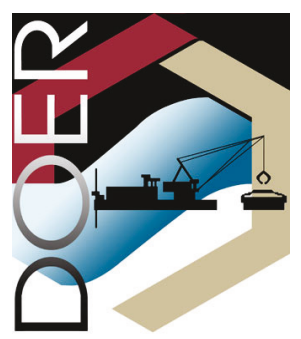

ERDC/TN DOER-D21

November 2018

\title{
Evaluation of Capacitance Staffs to Measure Vertical Accretion in Tidal Environments
}

by Brandon M. Boyd and Duncan B. Bryant

PURPOSE: This Dredging Operations and Environmental Research (DOER) Technical Note (TN) describes the effect of sediment deposition on water-level measurements taken via capacitance staff. During a field study, capacitance-type staffs used for wave measurement were buried by sediment. Analysis of this field data resulted in water-level minimums increasing through time. It was hypothesized that over time, the staffs were recording not the minimum water level but the increasing bed elevation. Laboratory experiments were designed to observe any effect of sediment burial on water-level measurements made using capacitance-type wave staffs.

\section{INTRODUCTION}

Motivation. Vertical accretion and surface elevation change are common metrics used in studying the geomorphology and viability of tidal marshes (Stoddart et al. 1989; Boyd and Sommerfield 2016). Methods of measurement include sediment traps and marker horizons that require installation and physical sampling, ground- or aerial-based survey methods that require repeat surveys at a desired temporal resolution, and geochemical methods that require significant analytical investment. Resolution of the accretion measurement using such approaches is limited to sampling frequency and thus often does not capture deposition and erosion associated with tidal, wind, and storm events. The contribution of such events as well as seasonal variations in emergent biomass to the accretion process is of utmost interest in ecology and numerical modeling (Fagherazzi et al. 2012). This study describes the serendipitous collection of a time series of surface elevation change by capacitance-type wave staffs and a laboratory evaluation aimed at determining such staffs' ability to measure accretion in tidal marshes. The use of capacitance to measure accretion in marshes and other intertidal settings represents a new application of these staffs in environments where measurement of accretion and erosion on short temporal scales has been traditionally difficult.

Capacitance wave staffs were deployed in a 7-month hydrodynamic study of a wetland-delta complex (Wax Lake, LA, USA) with rapid ( $>10$ millimeters [mm] per year) accretion to measure both waves and static water-levels (Styles et al. 2017). Upon recovery of the staff, it was observed that they were buried via vertical accretion of the delta platform primarily due to mineral sediment accumulation. Although wind and river discharge could result in days to weeks of inundation, low tide water-levels often resulted in the complete drainage of the delta platform. Such drying events were indicated by erroneous measurements by acoustic and optical sensors deployed in close proximity $(<0.5$ meter $[\mathrm{m}])$ to the staffs. Analysis of the staff water-level record showed an increase in the minimum height through time (Figure 1). The magnitudes of change in the minimum height were in agreement with independent measures of vertical 
accretion taken via feldspar marker horizon (Figure 1). Based on the water-level record's similarity to accretion measurements, it was hypothesized that the staffs were measuring the marsh surface when it was drained of tidal water. However, the behavior of the staffs when buried by sediment and the ability of the staffs to accurately measure the sediment surface could not be determined from the field data.

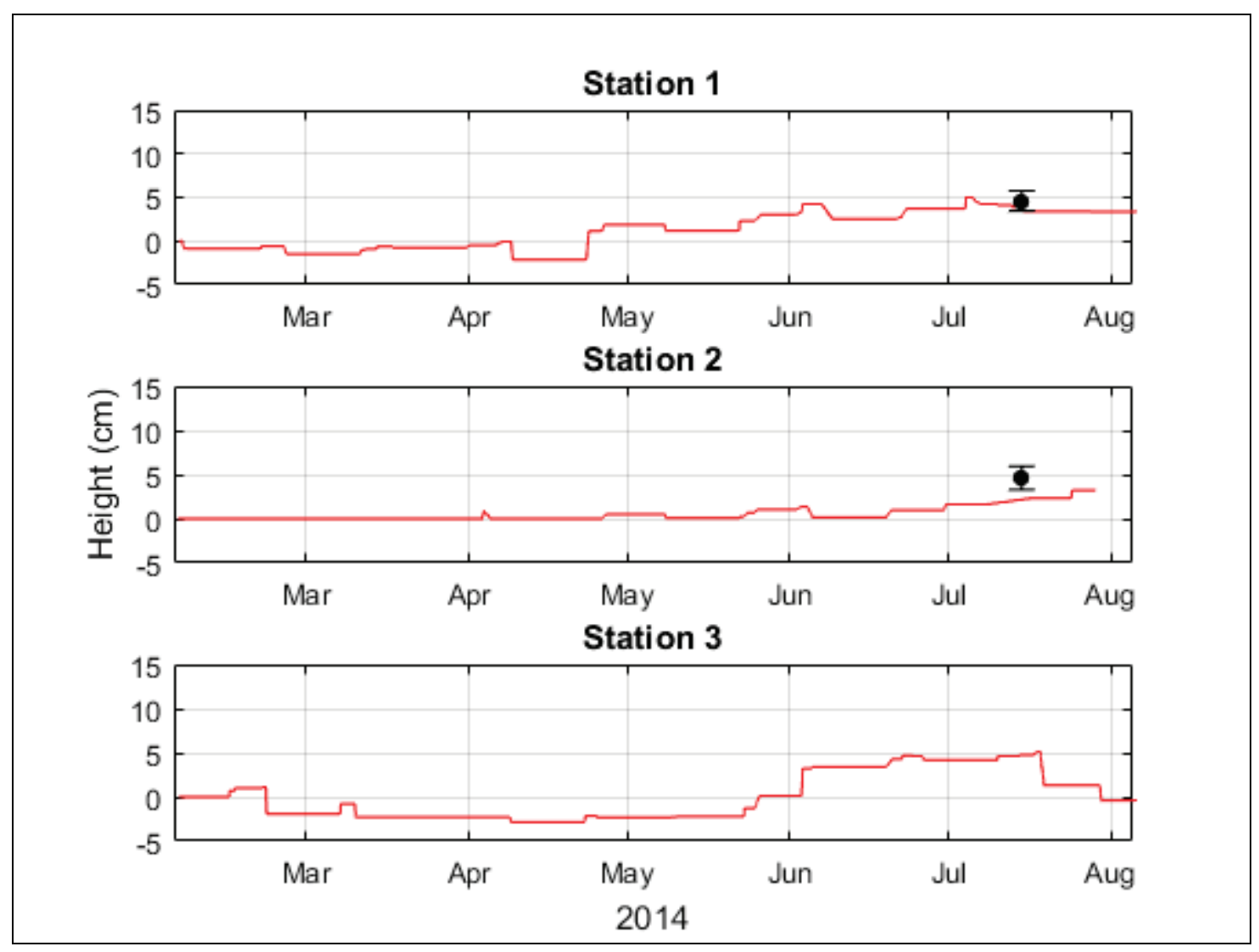

Figure 1. Weekly minimum water levels at three marsh stations at Wax Lake Delta, LA, USA. Net distance accreted, measured using marker horizon, shown as filled circle with standard error bars. No accretion rate could be determined at Station 3 where the marker horizon was not clearly identified. See Styles et al. (2017) for locations.

A laboratory evaluation was conducted to quantify the effects of sediment burial on two staffs commonly used in field and laboratory studies. The objectives were to determine (1) if a partially buried staff accurately identifies an overlying water surface and (2) if a drained sediment surface can be accurately detected. Based on behavior of the staffs during the field deployment, the hypotheses for the laboratory experiments were as follows: (1) sediment burial will not affect the staffs' response to water level and (2) the staffs will correctly measure the height of a drained sediment surface. These guiding hypotheses are based on the assumption that the staffs will correctly measure static water height as long as the capacitor circuit is maintained through a continuous conductor of water. It was assumed that, while the sediment could act as an additional insulator around the staff, its porosity would provide sufficient fluid contact with the staff thus minimizing any sediment insulation effects. This same porosity would trap sufficient fluid to maintain a circuit when overlying water would be drained and the sediment surface 
exposed to the air. To test the hypotheses, the response of the staffs was evaluated using two sediment treatments that consisted of being partially buried by sand and silt.

Capacitance-Type Wave Staffs. Capacitance wave staffs (hereafter, staffs) were being used as early as 1952 (Killen 1952) to measure water level and waves in a laboratory setting. Based on the principle of capacitance, these wave staffs use a wire or rod coated in a dielectric or insulating material as the first conductor. Water acts as the second conductor, changing the capacitance of the circuit as it rises and falls along the wire or rod. The change in capacitance is linearly proportional to the length of wire submerged given the wire or rod has a uniform diameter and the dielectric material has a uniform thickness (Campbell 1953).

Staffs have been successfully used in laboratory settings (Hudson et al. 1979) and to measure wave heights in estuaries (Kawai et al. 1977; Jones and Monismith 2007; Bricker et al. 2005). Waddell $(1973,1974)$ successfully used capacitance wave staffs to measure waves in the swash zone on a sandy beach. By burying a portion of the gauge, Waddell (1973) was able to measure the level of the saturated sand during wave backwash. Kraus and Smith (1994) also used capacitance wave staffs to measure the saturated sand level in a laboratory setting. Both of these studies were for sand substrates over a relatively short time scale. However, neither study investigated the effect of sediment burial on the performance of the wave staffs or the accuracy of the sediment level measurements.

Field Study Description. To better understand sediment- and hydro-dynamics in actively accreting delta, wave, current, and sediment sensors were deployed on four platforms January August 2014 on an interdistributary island at Wax Lake Delta, LA, USA (N 29²9'41.6" W 91 ${ }^{\circ} 6^{\prime} 49.6^{\prime \prime}$ ). An Ocean Sensor Systems (OSS) Model OSSI-010-002E wave staff interfaced with a $1 \mathrm{~m}$ sensing probe was deployed to measure waves and water level. The staffs were installed such that the end of the probe extended into a polyvinyl chloride (PVC) pipe cap sunk into the sediment surface (Figure 2). This configuration was to assure that the staffs would record across the full range of tide. It is presumed that the PVC pipe caps were quickly filled with sediment as they were observed to be filled with sediment $1-2$ months after deployment and completely buried during retrieval at six months. Additionally, two 1-centimeter (cm)-thick feldspar marker plots were established at each platform in January 2014 and sampled in July 2014. The plots were sampled by inserting a copper rod normal to the surface. The rod was then flushed with liquid nitrogen for sufficient time such that a frozen, intact core of sediment could be retrieved upon removal of the rod. The distance from the feldspar layer to the marsh surface was measured at $0^{\circ}, 90^{\circ}, 180^{\circ}$, and $270^{\circ}$ around the core using a micrometer. During sampling, the feldspar layer was clearly identified at Stations 1 and 2 but not at Station 3, where the amount of accretion could not be precisely determined. The net feldspar accretion distances are shown in Figure 1. The water-level record at Station 4 was incomplete due to equipment failure and is not presented here.

Acoustic Doppler velocimeters and optical back scatter sensors at each station were mounted $\sim 10 \mathrm{~cm}$ above the surface at deployment. When not submerged, these instruments produced a characteristic response that was used to determine when there was little to no water on the marsh surface. After filtering out periods when water was known to be on the marsh, the moving 14-day minimums of the wave staff record were assumed to represent marsh surface height (Figure 1). 


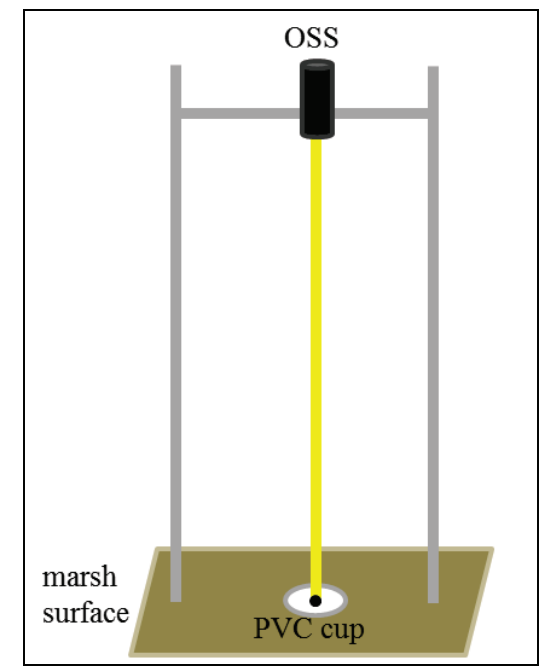

Figure 2. Illustration depicting the wave staff as installed at Wax Lake, LA, USA. A PVC end cap was set flush with the sediment surface. The OSS gauge was mounted on a cross member such that the capacitance rod was centered in the cup.

\section{METHODS}

Instrument Configuration and Calibration. Two capacitance-type wave-staffs were evaluated in the laboratory for sediment measurement: the Akamina Technologies Wave Height Gauge model AWP-24-3 with a $60 \mathrm{~cm}$ probe affixed with Teflon-coated 14 American Wire Gauge (AWG) sensing wire, hereafter referred to as Akamina, and the OSS Model OSSI-010$002 \mathrm{E}$ interfaced with a $1 \mathrm{~m}$ wave staff, hereafter referred to as OSS. The resolution for the Akamina and OSS was $0.0092 \mathrm{~mm}$ and $0.244 \mathrm{~mm}$, respectively. Staffs were powered by a common 12-volt (V) power supply and configured for analog voltage output. The output range for the OSS and Akamina was 0 to $5 \mathrm{~V}$ and -4.5 to $4.5 \mathrm{~V}$, respectively. A National Instruments cDAQ 9172 with a National Instruments 9125 data acquisition module (16 bit; $\pm 10 \mathrm{~V}$ ) controlled via LabView was used to $\log$ staff response at 10 hertz for 10 seconds (100 samples).

Evaluation of Linearity of Gauge Response. Due to the relatively height of the container used in the sediment treatments, the linearity of the gauge response was evaluated in a plexiglas cylinder. The main objective of this analysis was to determine the error associated with each gauge. The Akamina and OSS were evaluated at $5 \mathrm{~cm}$ intervals over 40 and $30 \mathrm{~cm}$ ranges, respectively. The deviations from a linear relationship (maximum residual from least squares regression) were used to determine the maximum gauge error. The range and standard deviation in voltage were determined for the 100 samples collected at each $5 \mathrm{~cm}$ step as measure of combined ambient, gauge, and acquisition system noise.

Experimental Design. A channelized-aluminum frame was constructed and leveled over a polypropylene tank. The staffs were mounted to the frame and remained fixed between 
treatments (Figure 3A). Water and sediment surface heights near each staff were determined using one of three point gauges all accurate to $0.3 \mathrm{~mm}$. All heights are referenced to the tank bottom $(0 \mathrm{~mm})$. The point gauge measuring the sediment surface height near the Akamina was mounted $\sim 4 \mathrm{~cm}$ from the probe. The point gauge measuring the sediment surface height near the OSS was $\sim 10 \mathrm{~cm}$ from the probe to avoid any interference from close proximity metallic objects, which had been observed in previous testing and calibrations. To minimize disturbance the sediment surface, a peristaltic pump and $1.5 \mathrm{~cm}$ diameter tubing was used to change the water level through a fine mesh well placed in the corner of the tank. Three datums, A ( $\sim 250 \mathrm{~mm}), \mathrm{B}$ $(\sim 173 \mathrm{~mm})$, and $\mathrm{C}(\sim 72 \mathrm{~mm})$, were marked on the tank to aid in achieving similar water or sediment levels between fills (Figure 3B). Sediment was added in slurry to height C (Figure 3B) for sand and silt treatments, and care was taken not to disturb the surface between fills. Using tap water $\left(2{ }^{\circ} \mathrm{C}\right)$ for the control and treatments, the water level was filled and drained three times to obtain replicate measurements at A, B, and C. During the sediment treatments, measurements at $\mathrm{C}$ were of the drained sediment surface.
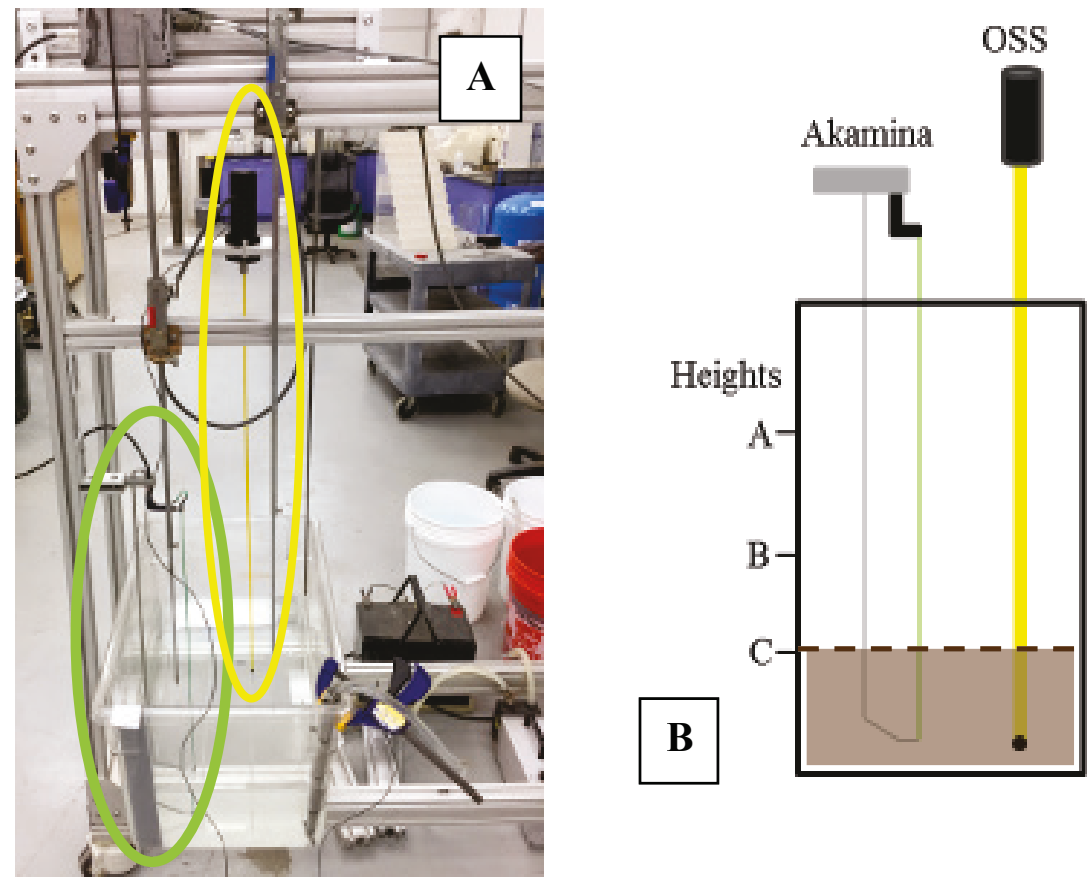

Figure 3. The wave staff and point gauge configuration used in the experiment (A) and illustration depicting the experimental setup and datums (B). The Akamina (green, left) and OSS (yellow, right) are shown in both panels. Three water heights ( $A, B$, and $C$ ) were used in the evaluation. For the sand and silt treatments, the sediment bed was constructed to height $\mathrm{C}$.

Sediment Treatments. Two sediment treatments were used to test the response of the staffs (Figure 4). The sand treatment was composed of well-sorted mined silica sand with a $d_{50}$ of $0.15 \mathrm{~mm}$. The silt treatment was composed of locally mined (Vicksburg, MS, USA) loess with $\mathrm{d}_{50}$ of $0.024 \mathrm{~mm}$. 


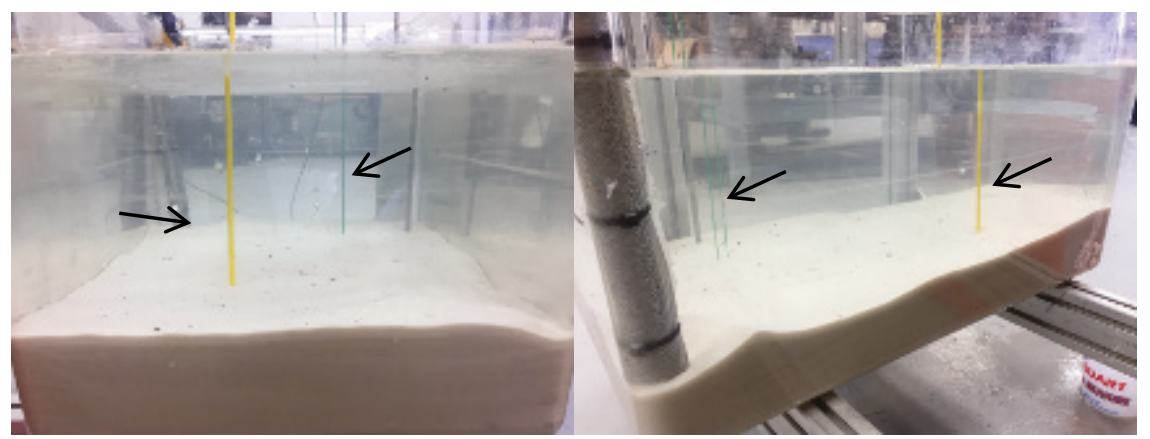

Figure 4. The sand treatment from two vantages. The Akamina (green) and OSS (yellow) are shown in both panels. The staffs are shown partially buried as they were during the sediment treatments. The metal mesh well is shown in the foreground of the right image. The configuration for the silt treatment was identical.

Statistical Analysis. As done in the linearity evaluation, the standard deviation of the voltage response for each 10 seconds sampling (100 samples) was used to represent uncertainty. The linearity of the staff response to water-level change was evaluated for all treatments using simple linear regression. Both staffs were known to produce a linear relationship between voltage and water level; thus, any deviation in this relationship would be assumed to be due to sediment burial. The slope of the linear response, the voltage and height relationship, was calculated for each replicate using simple linear regression. For both staffs, a one-way analysis of variance (ANOVA) was used to test for an effect of treatment on slope. In this design, the voltage-height relationship (slope) from two sediment treatments (sand and silt) was compared to the control treatment (water) for replicate runs.

The second hypothesis was tested by determining if the staffs could correctly measure the height of a drained sediment surface when no overlying water was present. The difference between the height measured via point gauge (point gauge height) and the height determined from each staff (staff height) was calculated for the water, sand, and silt surfaces at $\mathrm{C}$. These differences for the sand and silt bed levels were compared to the difference found for water level using a one-way ANOVA. The underlying assumption is that if the staffs measured the sediment surface, then the discrepancy between the heights from the point gauge and staff would be no different than for a water.

The R stats package (www.r-project.org) was used for analysis, and hypotheses were tested at a confidence level of $95 \%$. For all ANOVA, comparisons of water versus sand and water versus silt were planned. The ANOVA statistics are presented in the form of " $\mathrm{F} a, b=c, \mathrm{p}=d$ " where $a$. is the between-group degrees of freedom, $b$ is the within-group degrees of freedom, $c$ is the Fstatistic, and $d$ is the probability value.

\section{RESULTS}

Gauge Error and Linearity. The voltage response of the gauges was highly linear (Figure 5). 


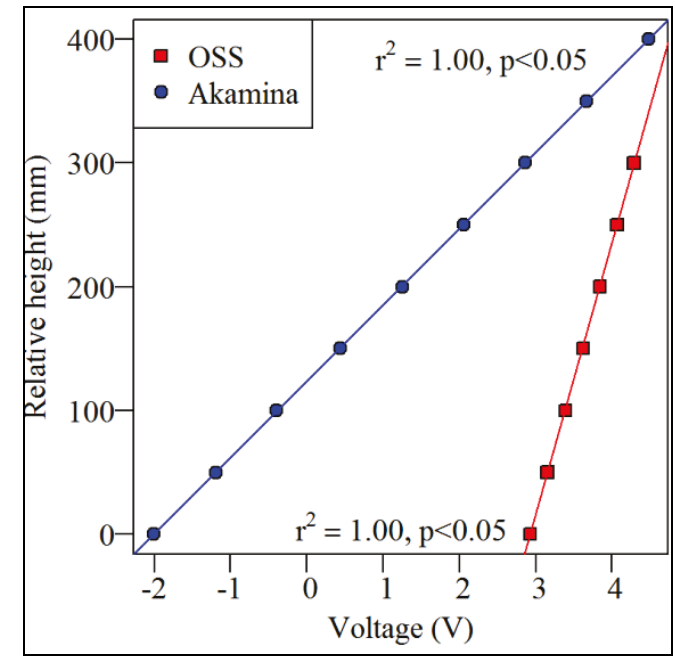

Figure 5. Linearity test showing regressions for the Akamina and OSS wave gauges.

The maximum error associated with the linear response of the gauges was found to be $0.12 \%$ and $0.18 \%$ of probe length equating to $0.04 \mathrm{~mm}$ and $0.18 \mathrm{~mm}$ for the Akamina and OSS, respectively.

Effect of Sediment Burial on Voltage-Height Relationship. There were $2.9 \mathrm{~mm}$ and $1.1 \mathrm{~mm}$ bed elevation differences between the two staff locations for sand and silt, respectively. These differences indicated that the sediment surfaces were not level and represent a source of uncertainty that must be considered in the analysis.

The voltage-height relationships for the Akamina (Figure 6A) and OSS (Figure 6B) were linear for the water, sand, and silt treatments.
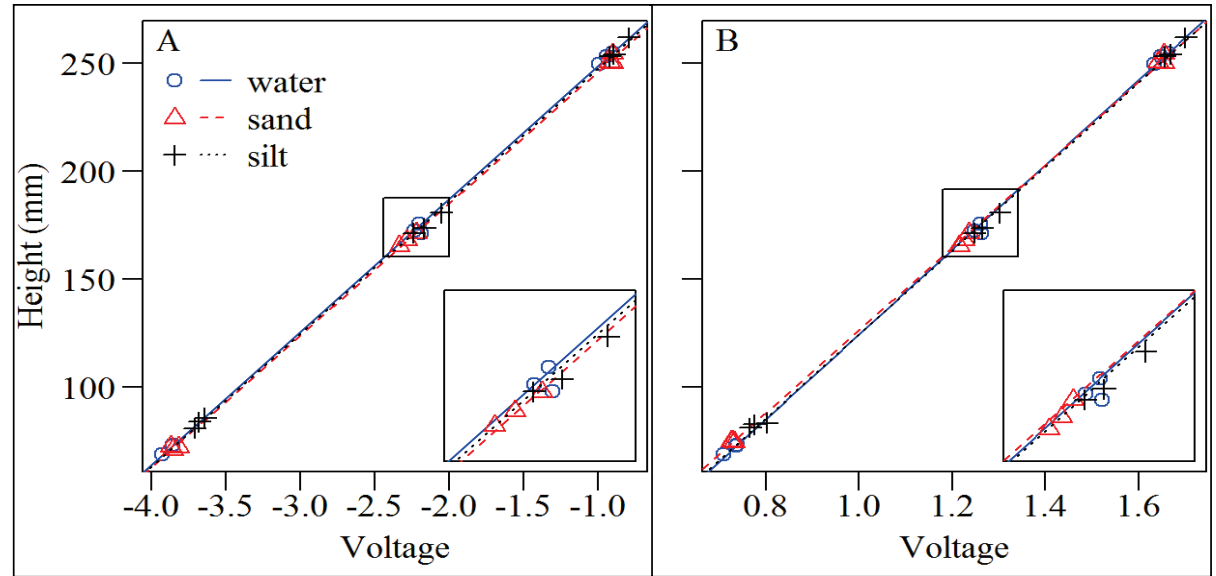

Figure 6. Scatterplot of depth and voltage for water, sand, and silt treatments for the Akamina (A) and OSS (B) staffs. Regression lines $\left(r^{2}=1.00\right)$ are shown for Akamina for water $(y=61.73 x+310.69)$, sand $(y=61.26 x+$ 307.69), and silt treatments $(y=61.69 x+309.56)$. Regression lines $\left(r^{2}=1.00\right)$ are shown for OSS staff for water $(y=196.63 x-72.37)$, sand $(y=192.04 x-65.85)$, and silt treatments $(y=194.60 x-70.44)$. 
To test the first hypothesis regarding the effect of sediment burial of the staff on measurement of the water surface, a one-way ANOVA was conducted comparing the voltage-height relationship during the water treatment with the voltage-height relationship during sediment treatments. No difference in the voltage-height relationship (slope) was observed between the control and sediment treatments for either the Akamina (sand: $F_{1,6}=0.838, p=0.395$ and silt: $F_{1,6}=0.011, p=$ 0.919 ) or the OSS (sand: $F_{1,6}=4.63, p=0.075$ and silt: $F_{1,6}=0.952, p=0.367$ ). Additionally, burial of the staffs by sediment did not appear to affect the standard deviation observed during sampling. For the Akamina, the standard deviation during the water, sand, and silt treatments was $0.032,0.035$, and $0.048 \mathrm{~mm}$, respectively. For the OSS, the standard deviation during the water, sand, and silt treatments was $0.43,0.44$, and $0.44 \mathrm{~mm}$, respectively.

Sediment Bed Elevation Measurements. To test the second hypothesis, the discrepancy between point gauge heights and staff heights for the water, sand, and silt surfaces was calculated (Figure 7). For sand and silt, the sediment surface was drained and measured three times. The staff heights were determined using the staff voltage, and the voltage-height regression was determined from the water treatment. See Figure 6 for equations. The discrepancies ranged 0.3 to $2.9 \mathrm{~mm}$ for Akamina and 0.4 to 4.3 for OSS (Figure 7). The discrepancies between the point gauge and staff heights for a water surface were not different than those for sand and silt surfaces when measured by the Akamina (sand: $\mathrm{F}_{1,6}=2.953, \mathrm{p}=0.137$ and silt: $\left.\mathrm{F}_{1,6}=0.824, \mathrm{p}=0.461\right)$ or the OSS $\left(\mathrm{F}_{1,6}=\right.$ 5.712, $\mathrm{p}=0.054$ and silt: $\mathrm{F}_{1,6}=0.081, \mathrm{p}=0.785$ ).

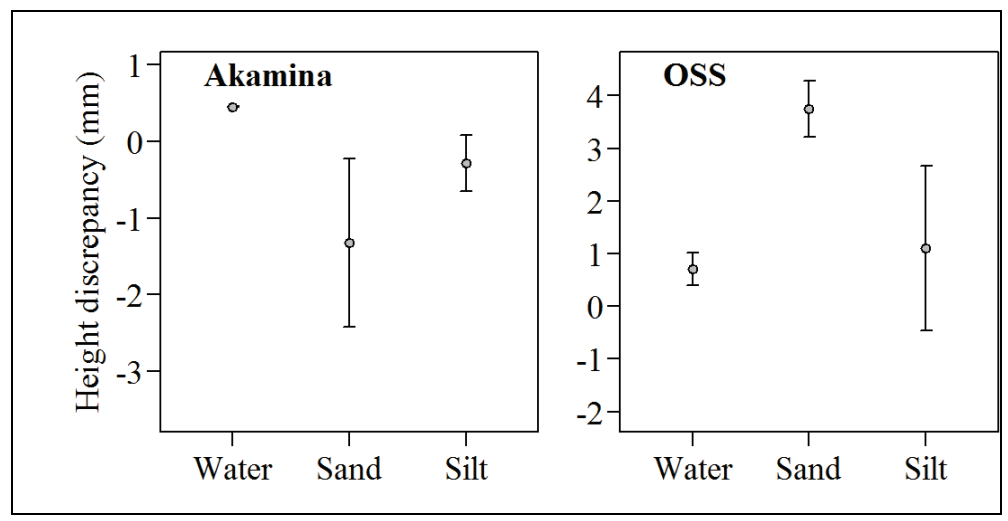

Figure 7. The discrepancy between actual and staff height measurements for a water, sand, and silt surface for the Akamina and OSS wave staffs. Plotted points and error bars represent the mean and standard error of three replicate measurements at Height $C$ (Figure 3B). See text for further discussion.

\section{DISCUSSION}

Experimental Error. The main source of error was the difference between the sediment elevation at the staff rod or wire and the point gauge. The water surfaces, minus inconsequential meniscus effects at tank edges, were level. However, as indicated by differences in bed elevation among the point gauges, a level surface was not achieved for the sand and silt treatments despite adding the sediments in slurry. The uniformity of the surface could be due to settling velocity of the sediment. The faster settling velocity of sand resulted in more variation in surface height 
$(+/-2.9 \mathrm{~mm})$. As expected the settling velocity of the silt was slower, and a more uniform surface $(+/-1.1 \mathrm{~mm})$ was achieved. The large discrepancies between the point gauge and staff height for the sediment treatments are likely due to the inability to measure the sediment surface directly at the staff with the point gauge. The staffs could be inserted into a leveled sediment bed of a known height; however, compaction due to insertion would affect porosity at the sediment-probe interface and create a void in the sediment larger than the staff probe itself. Thus, the addition of sediment via slurry best simulated sediment deposition as experienced by the staffs in the field albeit at accelerated rates compared to natural deposition.

Use of Wave Staffs for Measuring Accretion in Tidal Environments. The primary objective of this experiment was to verify the ability of the staffs to accurately identify an unburdened sediment surface thereby confirming a new method of measuring accretion and erosion in tidal marshes. During the field deployment, accretion measured via marker horizon was $45.95 \pm 11.61$ and $46.18 \pm 13.24 \mathrm{~mm} /$ year for Stations 1 and 2, respectively (Figure 1). Accretion could not be measured at Station 3 due to the incomplete retrieval of the marker layer, which was hypothesized as being due to erosion of the feldspar layer. Indeed, the record of bed height for Station 3 shows accretion initially in January with possible non-deposition and erosion occurring February through May. The uncertainty of the feldspar-based accretion measurements are two orders of magnitude greater than that of the laboratory experiment. In light of the experimental limitations discussed in the previous section, the staffs can track the sediment surface with a resolution in the millimeter to sub-millimeter range.

Comments and Recommendations. While the primary focus of this study was to confirm observations made in a tidal setting, the field observations and laboratory evaluation suggest that staffs can be used for accretion and erosion studies meeting certain criteria. First, the surface must be drained of water semi-regularly due to tidal or meteorological forcing. The measurement of bed elevation change is thereby limited to the frequency at which the sediment surface is completely drained. Second, additional equipment is required to identify low water and drainage events. For instance, a relatively inexpensive Conductivity-Temperature-Depth (CTD) sensor mounted near the sediment surface could be used for this task. Third, marsh soils have a wide range of the mineral sediment and organic matter content. The laboratory evaluation did not specifically address the effect of organic content, which could be evaluated in future testing. Nevertheless, it is likely that this capacitance method for measuring accretion and erosion would work in marsh soils with high organic content as long as they do not completely drain thereby removing porewater needed to complete the capacitor circuit.

ADDITIONAL INFORMATION: This DOER Technical Note was prepared by Drs. Brandon M. Boyd and Duncan B. Bryant of the U.S. Army Engineer Research and Development Center (ERDC), Coastal and Hydraulics Laboratory (CHL). This technical note should be cited as follows:

Boyd, B. M., and D. B. Bryant. 2018. Evaluation of Capacitance Staffs to Measure Vertical Accretion in Tidal Environments. ERDC/TN DOER-D21. Vicksburg, MS: U.S. Army Engineer Research and Development Center. http://dx.doi.org/10.21079/11681/30623 


\section{ERDC/TN DOER-D21}

\section{November 2018}

\section{REFERENCES}

Boyd, B. M., and C. K. Sommerfield. 2016. "Marsh Accretion and Sediment Accumulation in a Managed Tidal Wetland Complex of Delaware Bay." Ecological Engineering 92: 37-46. doi:10.1016/j.ecoleng.2016.03.045.

Bricker, J. D., S. Inagaki, and S. G. Monismith. 2005. "Bed Drag Coefficient Variability under Wind Waves in a Tidal Estuary." Journal of Hydraulic Engineering 131: 497-508.

Campbell, W. S. 1953. An Electronic Wave-Height Measuring Apparatus. Report No. 859. David Taylor Model Basin, U.S. Navy, Washington, DC.

Fagherazzi, S., M. L. Kirwan, and S. M. Mudd. 2012. "Numerical Models of Salt Marsh Evolution: Ecological, Geomorphic, and Climatic Factors." Reviews of Geophysics 50: 1-28. doi:10.1029/2011RG000359.1. INTRODUCTION.

Hudson, R. Y., F. A. Herrmann, R. A. Sager, R. W. Whalin, G. H. Keulegan, C. E. Chatham, and L. Z. Hales. 1979. Coastal Hydraulic Models: Special Report No. 5. Fort Belvoir, VA: Coastal Engineering Research Center, U.S. Army Corps of Engineers.

Jones, N. L., and S. G. Monismith. 2007. "Measuring Short-Period Wind Waves in a Tidally Forced Environment with a Subsurface Pressure Gauge." Limnology and Oceanography: Methods 5: 317-327.

Kawai, S., K. Okada, and Y. Toba. 1977. "Field Data Support of Three-Seconds Power Law and $g \mu_{*} \sigma^{-4}$ Spectral Form for Growing Wind Waves." Journal of the Oceanographical Society of Japan 33: 137-150.

Killen, J. M. 1952. A Capacitive Type Wave Recorder. Technical Paper No. 11, Series B. St. Anthony Falls Hydraulic Laboratory, University of Minnesota, Minneapolis, MN.

Kraus, N. C., and J. M. Smith. 1994. SUPERTANK Laboratory Data Collection Project, Volume 1: Main Text. Technical Report CERC 94-3. Vicksburg, MS: Waterways Experiment Station, U.S. Army Corps of Engineers.

Stoddart, D., D. J. Reed, and J. R. French. 1989. "Understanding Salt-Marsh Accretion, Scolt Head Island, Norfolk, England." Estuaries and Coasts 12: 228-236. doi:10.2307/1351902.

Styles, R., D. Bryant, J. Gailani, J. Smith, and G. Snedden. 2017. Sediment Dynamics in a Vegetated Tidally Influenced Interdistributary Island: Wax Lake, Louisiana. ERDC/CHL TR-17-12. Vicksburg, MS: U.S. Army Engineer Research and Development Center.

Waddell, E. 1973. Dynamics of Swash and Implications to Beach Response. Technical Report No. 139. Coastal Studies Institute, Louisiana State University, Baton Rouge, LA.

Waddell, E. 1974. "Swash-Groundwater-Beach Profile Interactions.“"In Beach and Nearshore Sedimentation. Edited by R. A. Davis, Jr. and R. L. Ethington, 115-125. Society of Economic Paleontologists and Mineralogists. Special Publication No. 24.

NOTE: The contents of this technical note are not to be used for advertising, publication, or promotional purposes. Citation of trade names does not constitute an official endorsement or approval of the use of such products. 